\title{
Case Report and Review of the Literature
}

\section{Kidney Transplant and Ileal Conduit Diversion on the Same Surgical Procedure: Clinical Case and Review of the Literature}

\author{
P. Doménech López ${ }^{1 *}$, J.E. Robles García ${ }^{1}$, J. Colombás Vives ${ }^{1}$, C. Gutiérrez Castañ é ${ }^{1}$, S. Chiva ${ }^{1}$, A. García Cortés ${ }^{1}$, F.J. \\ Ancizu Marckert ${ }^{1}$, G. Barbas Bernardos ${ }^{2}$, M. Torres Roca ${ }^{1}$, G. Andrés Boville ${ }^{2}$, F. Ramón de Fata Chillón ${ }^{2}$, F. \\ Villacampa Aubáa $^{2}$, D. Rosell Costa ${ }^{1}$, F.J. Diez-Caballero Alonso ${ }^{1}$, B. Miñana López ${ }^{2}$ and J.I. Pascual Piédrola \\ ${ }^{1}$ Clínica Universitaria de Navarra, Pamplona, Spain \\ ${ }^{2}$ Clínica Universitaria de Navarra, Madrid, Spain
}

\begin{tabular}{l} 
A R T I C L E I N F O \\
\hline Article history: \\
Received: 8 May, 2020 \\
Accepted: 20 May, 2020 \\
Published: 3 June, 2020 \\
\hline Keywords: \\
Ileal conduit \\
kidney transplantation \\
transplant procedures \\
neurogenic bladder
\end{tabular}

\begin{abstract}
A B S T R A C T
Introduction: There are multiple causes of end-stage renal disease (ESRD). One of the most uncommon cause is the obstruction of the lower urinary tract due to the development of new endourological procedures and the improvement in clean intermittent catheterization. However, urodynamic problems that require solutions to bladder problems continue to appear that will directly affect the function of the kidney graft. Objective: Clearly state the possibility of performing a bladder conduit technique at the same time as a kidney transplant as an option for patients who undergo kidney transplantation with incompetent bladders. A clinical case is described as an example.

Material and Methods: The clinical case of a patient with left cutaneous ureterostomy due to neurogenic bladder who is a candidate for renal transplant is presented. An ileal conduit type urinary diversion is performed in the same surgical act as the renal transplant. The existing literature is analyzed in relation to the different types of urinary diversion and how they affect renal function.

Clinical Case and Results: Here we present a 50-year-old male with hypotonic bladder since $19^{\text {th }}$ years old secondary to sacral lipectomy. He developed a progressive deterioration of renal function until he started hemodialysis program in 2018. Ileal conduit and renal transplant are performed through right pararectal incision, reimplantation of the ureter in the antimesenteric side of the intestinal loop. No increase of complications was observed in the post-transplant. The patient was discharged the 7 th day after surgery. Serum creatinine at 6 months after renal transplantation $1.2 \mathrm{mg} / \mathrm{dl}$.

Conclusion: Ileal conduit is a valid resource in patients with neurogenic bladders or with emptying problems whose solution puts at risk the functionality of the graft. Similar recovery is observed in time compared to a kidney transplant without ileal shunt. Post-transplant graft function was good without an increase in complications.
\end{abstract}

๑ 2020 Pablo Doménech López. Hosting by Science Repository.

\section{Introduction}

Chronic renal disease is defined as the presence during at least three months of glomerular filtrate less than $50 \mathrm{ml} / \mathrm{min} / 1.73 \mathrm{~m}^{2}$ or renal injury affecting the functionality of the kidney [1]. The lesion can be objectified histologically, by imaging or by hydro electrolytic alterations in blood or urine samples when the cause is demonstrated to be renal [2]. The prevalence of this clinical entity is increasing due to demographic evolution, population aging and changes in diet, with the increased incidence of diabetic nephropathy [3]. Nearly $10 \%$ of the adult population suffers at least some degree of renal failure, a percentage that rises to over $20 \%$ in people over 65 years of age $[2,4]$.

"Correspondence to: Pablo Doménech López, Department of Urology, Clínica Universitaria de Navarra, Pío XII Avenue 36, 31008, Pamplona, Navarra, Spain; Tel: 655889225; E-mail: pablodomenechlopez.md@gmail.com; pdomenech@unav.es 
A significant percentage of these patients will require renal replacement therapy, where we find the modalities of hemodialysis, peritoneal dialysis and renal transplantation in favorable cases. The morbimortality associated with chronic renal pathology is high, observing a higher mortality in waiting list for renal transplant than in transplanted patients, even with expanded criteria donors [5]. There are multiple causes of endstage renal failure. One of the most uncommon causes in the adult population is obstruction of the common urinary tract due to the development of unobstructive surgery and improvement in clean intermittent catheterization, although in pediatric age obstructive causes can account for up to $25 \%$ of renal failure [6]. However, urodynamic problems continue to arise that require solutions to bladder problems that will directly affect the function of the graft.

\section{Objectives}

To analyze the alternatives in patients who are candidates for kidney transplant with an incompetent lower urinary system that requires urinary diversion in the same surgical act.

\section{Material and Methods}

The clinical case of a patient with left cutaneous ureterostomy due to neurological bladder involvement who is a candidate for renal transplant is presented. An ileal conduit type urinary diversion is performed in the same surgical act as the renal transplant. The existing literature is analyzed in relation to the different types of urinary diversion and how they affect renal function.

A search is performed using the PUBMED search engine with the terms "Kidney transplantation" and "ileal bladder" obtaining 2 results. The search is extended with the terms "kidney transplant" ileal bladder giving 23 results. Once the articles have been analyzed, it is verified that in no case is an intervention with ileal derivation found at the same time. Most published clinical cases compare renal function after cystectomy because of tumoral pathology after transplantation.

\section{Clinical Case}

A 50-year-old male with hypotonic bladder since he was 19 years old secondary to sacral lipectomy requiring self-catheterization due to elevated bladder residue. He presents progressive renal function deterioration due to bladder emptying deficit and urinary infections leading to stenosis of the ureterovesical union by fibrosis and micro bladder. For this reason, double $\mathrm{J}$ catheters are placed with periodic replacements from 2015. Due to the persistence of episodes of urinary infection and pyelonephritis with progressive deterioration of renal function, cutaneous ureterostomy is placed in the left flank. He developed end stage renal disease and was admitted to the home hemodialysis program in 2018 with residual diuresis of 2 liters.

At last, he came to our center to be evaluated as a candidate for a kidney transplant entering waiting list. Abdominal urethrocystography and CT scan are performed showing a micro bladder with no storage capacity, totally defunct, thus ruling out the possibility of ureteral reimplantation on native bladder. With the tests carried out, ileal conduit type urinary diversion in the same surgical act was the election to solve his urodynamic problems without compromising future renal function.

In May 2019, a kidney transplant is performed under general anesthesia through a right para-rectal incision with a bowel loop preparation according to Bricker's technique. Renal transplant is performed in the right external iliac artery and right external iliac vein with distal ureteral implantation. Satisfactory post-transplant recovery with discharge after the 7 th day of admission. Serum creatinine at discharge was $2.5 \mathrm{mg} / \mathrm{dl}$, at first month review $1.4 \mathrm{mg} / \mathrm{dl}$ and on the review of the sixth month, 1.2 $\mathrm{mg} / \mathrm{dl}$. He did not suffer any infection of adverse event secondary to the urinary diversion.

\section{Discussion}

Chronic kidney disease in the adult population is due to multiple causes such as diabetic nephropathy, hypertension or glomerular involvement. Obstruction of the lower common tract as a cause of end-stage renal disease is an uncommon pathology that affects $6 \%$ of patients with chronic renal disease, either from congenital or acquired causes [7]. The neurological pathology causing chronic renal disease leads to an obstruction of the common functional tract affecting renal emptying.

In the above case, low spinal cord damage with upper motor neuron involvement causes sphincter hypertonia, bladder hypotonia and lack of sensation with bladder filling. In addition, bladder emptying dysfunction and elevated post-voidal residues increases the risk of recurrent urinary tract infections. The pyelonephritis that the patient has suffered has caused a fibrosis that leads to bilateral ureteral stenosis and micro bladder. Scars can also be seen at the renal level as a result of pyelonephritis. The decision to derive the ureters to skin by means of ureterostomy in the left flank allows us to preserve the right side for a future renal transplant due to the deterioration that already existed when that intervention was considered. The use of ureterostomy is a valid technique in patients with complex pathology or as a previous step to urinary tract reconstruction $[8,9]$.

In healthy individuals, it is estimated that approximately $9.1 \mathrm{ml} / \mathrm{min} / 1.73 \mathrm{~m}^{2}$ is lost every decade after the age of 40 [9]. Urinary diversion, either by ileal conduit or continent bladder, can lead to more rapid deterioration of renal function due to the increased risk of urinary tract infections in healthy patients. The use of urinary diversion in transplanted patients has not demonstrated a greater loss of the renal graft nor has it been seen to be an independent factor in the deterioration of renal function $[10,11]$. The study by Zabell et al. did observe an increased risk of developing renal failure in patients cystectomized by urothelial tumor with a survival of more than 5 years, so in the long term the benefits of urinary diversion in a transplanted patient must be taken into account [12].

In the study by Surange et al. analyzed all kidney transplants performed between 1980 and 2002, observing 59 cases of ileal conduit kidney transplantation, with the same percentages of graft survival compared to the rest of the series of 2579 transplants, which supports ileal bladder kidney transplantation [13]. Gilbert's studies also observed no difference between the type of shunt and the deterioration of renal function [14]. 
The main complication of this type of kidney transplant is urinary tract infection, although it has not been seen to have a significant mediumterm impact on kidney grafts [15]. Adequate prophylaxis and strict follow-up of the patient can avoid most of the complications resulting from the infections. The main cause of renal graft failure remains rejection, whether acute or chronic. In experimental models no increase in renal failure has been seen due to transplantation concomitant with ileal deviation [16]. Chronic renal disease is a clinical condition that affects the quality of life and survival of the patient. It is associated with increased cardiovascular disease and diabetes, so transplantation prevents mortality and morbidity in properly selected patients. Chronic renal disease costs around 800 million euros a year in Spain, so the development of surgeries that allow transplants to be performed earlier and with less time on dialysis would improve quality of life in the long term [17].

\section{Conclusion}

Early diagnosis and management of the urinary tract is essential to prevent the progression of kidney disease that can lead to loss of kidney function. Ileal bladder bypass is a valid option for patients with incompetent bladders or voiding problems whose solution puts longterm kidney function at risk. Ileal conduit urinary diversion is a safe technique that can be used in patients with urodynamic problems or with an unviable lower urinary system without increasing the risk of early graft loss. No more surgical complications have been observed in the operation performed compared to a conventional kidney transplant. Similar recovery in time is observed compared to a kidney transplant without ileal shunt with early and good medium-term function.

\section{Conflicts of Interest}

None.

\section{Funding}

None.

\section{REFERENCES}

1. Improving Global Outcomes (KDIGO) CKD Work Group (2013) KDIGO Clinical Practice Guideline for the Evaluation and Management of Chronic Kidney Disease. Kidney Int 3: S6-S308.

2. Castelao AM, Górriz JL, Bover J, Segura de la Morena J, Cebollada J et al. (2014) Documento de consenso para la detección y manejo de la enfermedad renal crónica Alberto. Aten Primaria 46: 501-519. [Crossref]
3. Kurokawa K, Nangaku M, Saito A, Inagi R, Miyata T et al. (2002) Current Issues and Future Perspectives of Chronic Renal Failure. J Am Soc Nephrol 1: S3-S6. [Crossref]

4. Otero A, de Francisco A, Gayoso P, Garcia F, EPIRCE Study Group (2010) Prevalence of Chronic Renal Disease in Spain: Results of the EPIRCE Study. Nefrologia 30: 78-86. [Crossref]

5. Ojo AO, Hanson JA, Meier Kriesche H, Okechukwu CN, Wolfe RA et al. (2001) Survival in Recipients of Marginal Cadaveric Donor Kidneys Compared with Other Recipients and Wait-Listed Transplant Candidates. J Am Soc Nephrol 12: 589-597. [Crossref]

6. Djakovic N, Wagener N, Adams J, Gilfrich C, Haferkamp A et al. (2009) Intestinal Reconstruction of the Lower Urinary Tract as a Prerequisite for Renal Transplantation. BJU Int 103: 1555-1560. [Crossref]

7. Salido EA, Candau RB, Torrubia Romero FJ, Navarro NC, Montañés Medina JLAP (2004) Ampliación vesical y derivación urinaria en pacientes candidatos a trasplante renal. Arch Esp Urol 57: 7.

8. Tayib AM, Alsayyad AJ (2012) Management of Obstructive Uropathy With Cutaneous Ureterostomy in Posterior Urethral Valve. Saudi $J$ Kidney Dis Transpl 23: 355-357. [Crossref]

9. Grewal GS, Blake GM (2005) Reference Data for 51Cr-EDTA Measurements of the Glomerular Filtration Rate Derived from Live Kidney Donors. Nucl Med Commun 26: 61-65. [Crossref]

10. Fournier R, Codas Duarte R, Daily T, Martin X, Badet L et al. (2017) Long-term Kidney Transplant Survival in Patients with Continent Urinary Diversion. Int J Urol 24: 787-792. [Crossref]

11. Eisenberg MS, Thompson RH, Frank I, Kim SP, Cotter KJ et al. (2014) Long-term Renal Function Outcomes After Radical Cystectomy. J Urol 191: 619-625. [Crossref]

12. Zabell JR, Adejoro O, Konety BR, Weight CJ (2015) Risk of End Stage Kidney Disease After Radical Cystectomy According to Urinary Diversion Type. J Urol 193: 1283-1287. [Crossref]

13. Surange RS, Johnson RW, Tavakoli A, Parrott NR, Riad HN et al. (2003) Kidney Transplantation into an Ileal Conduit: A Single Center Experience of 59 Cases. J Urol 170: 1727-1730. [Crossref]

14. Gilbert SM, Lai J, Saigal CS, Gore JL, Urologic Diseases in America Project (2013) Downstream Complications Following Urinary Diversion. J Urol 190: 916-922. [Crossref]

15. Broniszczak D, Ismail H, Nachulewicz P, Szymczak M, Drewniak T et al. (2010) Kidney Transplantation in Children With Bladder Augmentation or Ileal Conduit Diversion. Eur J Pediatr Surg 20: 5-10. [Crossref]

16. Haberal M, Kirnap M, Gokce ON, Bacanli D, Ersoy Z et al. (2018) Technique of Ileobladder and Kidney Transplant in Rats and Pigs. Exp Clin Transplant 16: 1-9. [Crossref]

17. De Francisco ALM (2011) Sostenibilidad y equidad del tratamiento sustitutivo de la función renal en España. Nefrologia 31: 241-246. 